九州大学学術情報リポジトリ

Kyushu University Institutional Repository

\title{
Continuous high-pressure torsion
}

\section{Edalati, Kaveh}

Department of Materials Science and Engineering, Faculty of Engineering, Kyushu University

Horita, Zenj i

Department of Materials Science and Engineering, Faculty of Engineering, Kyushu University

http://hdl. handle. net/2324/26393

出版情報: Journal of Materials Science. 45 (17)，pp.4578-4582，2010-09-01. Springer US バージョン:

権利関係: (C) Springer Science+Business Media, LLC 2010 


\title{
Continuous high-pressure torsion
}

\section{Kaveh Edalati $^{\mathrm{a}, *}$ and Zenji Horita ${ }^{\mathrm{a}}$}

Department of Materials Science and Engineering, Faculty of Engineering, Kyushu University, Fukuoka 819-0395, Japan

* e-mail: kaveh.edalati@zaiko6.zaiko.kyushu-u.ac.jp

\begin{abstract}
Continuous high-pressure torsion (CHPT) was developed as an expeditious process to attempt severe plastic deformation. Using the CHPT, sheets of high purity aluminum, copper and iron were successfully processed by introducing intense shear strain under high pressure. The results of hardness measurements after CHPT were well consistent with those of conventional high-pressure torsion using disc and ring specimens. Microstructural observations demonstrated that CHPT can be used as a continuous process for grain refinement.
\end{abstract}

\section{Introduction}

Significant grain refinement is achieved by processing metallic materials through the application of severe plastic deformation (SPD) [1]. Several methods were developed for the SPD process, which mainly include equal-channel angular pressing (ECAP), high-pressure torsion (HPT), accumulative roll-bonding (ARB), multi directional forging (MDF), cyclic extrusion and compression (CEC) and repetitive corrugation and strengthening (RCS) [2]. Among different techniques for the SPD process, HPT is especially effective to introduce extremely large shear strains for the grain refinement. Because the HPT is operated under high hydrostatic pressures, the fracture is significantly suppressed and thus it is applicable to hard and less ductile materials such as molybdenum [3], tungsten [4] and intermetallics [5]. In the HPT method which was first invented by Bridgman in 1935 [6], a small thin disc is placed between two massive anvils under a high pressure and intense shear strain is introduced by rotating the two anvils with respect to each other.

The HPT process has three main limitations: first, the sample shape is in a form of disc which is not appropriate for many industrial applications when compared to wire or sheet forms; second, the sample size is generally limited to a maximum of $35 \mathrm{~mm}$ in diameter in order to keep a high applied pressure; third, because the strain is generated in proportion to the distance from the disc center, an inhomogeneous distribution of microstructure is developed across the diameter. In order to overcome these limitations, the HPT using ring shape, which is more appropriate than disc shape for industrial application, was introduced [7] with a simple modification of the earlier design 
[8, 9]. Using the ring HPT, it is possible not only to eliminate a less-strained and coarse-grained center part [7, 10,11] but also to scale up the sample, for example to $100 \mathrm{~mm}$ in diameter [12]. In another attempt to improve the sample shape, the high-pressure sliding (HPS) was developed for producing sheet metallic materials with $5 \mathrm{~mm}$ width, $0.8 \mathrm{~mm}$ thickness and $100 \mathrm{~mm}$ length [13]. In both ring HPT and HPS, the sample size is still limited because the pressure is sacrificed with any increase in the sample size. For example, in order to process with HPT for disc with 500mm diameter under a pressure of $2 \mathrm{GPa}$, the compression load should be 39000 tons. In order to process with HPT for a ring with $500 \mathrm{~mm}$ in outer diameter and 3mm width under a pressure of $2 \mathrm{GPa}$, the compression load should be 940 tons. For HPS processing of a sheet with 500mm length and $5 \mathrm{~mm}$ width under a pressure of $2 \mathrm{GPa}$, the compression load should be 500 tons.

In this study, thus, a new alternative SPD process is developed for processing of metallic sheets with HPT in a continuous way, which we call continuous high-pressure torsion (CHPT). Using the CHPT, the sample is processed in an expeditious way so that the sample size is increased without sacrificing the pressure.

\section{Experimental Materials and Procedures}

The facility for the CHPT, as schematically illustrated in Fig. 1, consists of two anvils: the lower anvil, which is rotated during process, has a flat surface with a roughened ring-shaped area; and the upper anvil, which is fixed during process, has a half ring-shaped groove on the surfaces with $0.5 \mathrm{~mm}$ depth, $3 \mathrm{~mm}$ width and outer diameter $(O D)$ of 20 or $30 \mathrm{~mm}$. The surface roughness of the upper anvil is reduced with respect to the surface roughness of the lower anvil to induce a continuous flow of the material due to the difference in slippage. A U-shaped specimen with $1 \mathrm{~mm}$ thickness, as shown in Fig. 1, is used as an initial sample. Each sample is placed on the lower anvil and the pressure is applied on the sample by raising the lower anvil up to a rigid contact with the upper anvil. The lower anvil is then rotated with respect to the upper anvil and shear strain is introduced in the sample under a high pressure. Accordingly the material starts to flow in the rotation direction. Fig. 2 shows the appearance of a $\mathrm{Cu}$ sample with $O D=20 \mathrm{~mm}$ before and after CHPT.

The equivalent strain produced by CHPT, $\varepsilon$, is estimated as

$$
\varepsilon=(1-s) \frac{\pi R}{\sqrt{3} t}
$$

where $s$ is the fraction of sample slippage, $R$ is the mean radius of U-shaped sample, as shown in Fig. 2, and $t$ is the thickness of sample. For this study, $R$ was either 8.5 or $13.5 \mathrm{~mm}$ and $t$ was 0.6 $\mathrm{mm}$. The slippage was evaluated, as described in detail in an earlier report [14], by measuring the discrepancy of the markers made on both surfaces of the sample after rotating by a quarter revolution $\left(90^{\circ}\right)$. It was turned out that the slippage was negligibly small for the first quarter revolution for all of $\mathrm{Al}, \mathrm{Cu}$ and $\mathrm{Fe}$. However, the revolution by $180^{\circ}$ led to disappearance of the markers so that slippage occurred during another $90^{\circ}$ revolution. Although rigorous estimation was not possible, the slippage can be of $0<\mathrm{s}<1 / 2$ in this study. 
The experiments were conducted using high-purity $\mathrm{Al}$ (99.99\%), $\mathrm{Cu}$ (99.99\%) and $\mathrm{Fe}$ (99.96\%) sheets, which match the materials used in the earlier reports for conventional HPT [10-12]. The sheets were then cut to U-shaped specimens, as shown in Fig. 3, with $1 \mathrm{~mm}$ thickness, 3mm width, outer diameter of $O D=20$ or $30 \mathrm{~mm}$ and 40 to $80 \mathrm{~mm}$ length. The $\mathrm{Al}$ and $\mathrm{Cu}$ specimens were annealed at $773 \mathrm{~K}$ and $873 \mathrm{~K}$ for 1 hour, respectively. Each sample was placed on the lower anvil, and the upper and lower anvils were rotated with respect to each other at room temperature with a rotation speed of $1 \mathrm{rpm}$ under a selected pressure of $1 \mathrm{GPa}$ for $\mathrm{Al}$ and $2 \mathrm{GPa}$ for $\mathrm{Cu}$ and Fe. The rotation was terminated after 2 revolutions.

Following CHPT, the samples were subjected to Vickers microhardness measurement and evaluated using electron back-scatter diffraction (EBSD) analysis and transmission electron microscopy (TEM).

First, both sides of the sample were polished to a mirror-like surface and the Vickers microhardness was measured at 16 points on upper and lower surfaces of the sample. Hardness was measured along the length in the center portion at every $1 \mathrm{~mm}$ starting from $5 \mathrm{~mm}$ away from the exit of the upper anvil, as drawn by dotted lines in Fig. 3. The samples were further ground and polished mechanically and the hardness was measured on the surface at the middle point of thickness. For each hardness measurement, a load of $50 \mathrm{~g}$ for $\mathrm{Al}$ and a load of $200 \mathrm{~g}$ for $\mathrm{Cu}$ and $\mathrm{Fe}$ were applied for 15 seconds and the average of hardness values on the upper surface, lower surface and the surface at the middle point of thickness was calculated.

Second, discs with $3 \mathrm{~mm}$ in diameter were punched from the HPT discs at $5 \mathrm{~mm}$ away from the exit of the upper anvil as also illustrated in Fig. 3 . The $3 \mathrm{~mm}$ discs were ground mechanically to a thickness of $0.4 \mathrm{~mm}$ and further polished with a electro-chemical polisher using a solution of $10 \%$ $\mathrm{HClO}_{4}, 20 \% \mathrm{C}_{3} \mathrm{H}_{8} \mathrm{O}_{3}$ and $70 \% \mathrm{C}_{2} \mathrm{H}_{5} \mathrm{OH}$ for $\mathrm{Al}, 15 \% \mathrm{HNO}_{3}, 15 \% \mathrm{C}_{3} \mathrm{H}_{5}(\mathrm{OH})_{3}$ and $70 \% \mathrm{CH}_{3} \mathrm{OH}$ for $\mathrm{Cu}$ and $10 \% \mathrm{HClO}_{4}$ and $90 \% \mathrm{CH}_{3} \mathrm{COOH}$ for Fe. EBSD analysis was performed at a voltage of 20 $\mathrm{kV}$ and the crystal orientations were determined using an automatic beam scanning system.

Third, for TEM, the 3mm disc samples used for the EBSD analysis were ground mechanically to a thickness of $0.15 \mathrm{~mm}$ and further thinned with a twin-jet electro-chemical polisher using the solutions as mentioned above. TEM was performed at a voltage of $200 \mathrm{kV}$ for microstructural observation and for recording selected-area electron diffraction (SAED) patterns.

\section{Results and Discussion}

Fig. 4 plots the thickness variation against the distance, $L$, along the longitudinal direction for (a) Al, (b) $\mathrm{Cu}$ and (c) Fe after processing with CHPT. The definition of $L$ is shown in Fig. 2. The thickness is reduced from 1.0 to $\sim 0.6 \mathrm{~mm}$ by CHPT and it is almost uniform for $L>10 \mathrm{~mm}$.

The hardness measured on the upper surface and the lower surface including the surface at the middle point of thickness for samples with $O D=20$ and $30 \mathrm{~mm}$ are given in Table 1 . It is found that the hardness is reasonably the same on upper, middle and lower surfaces, indicating a uniform microstructural evolution across the sample thickness. The average of hardness among the upper, middle and lower surfaces was taken for each sample and plotted in Fig. 5 together with earlier data obtained by conventional HPT of (a) Al, (b) Cu and (c) Fe using disc and ring specimens [10-12]. 
There are two main points to be noted regarding the plots in Fig. 5: first, the results of HPT and CHPT are consistent except somewhat higher value obtained for Fe processed with CHPT; and second, the hardness values for CHPT processed samples lie well on the steady state (saturated) level obtained for disc samples and ring samples after processing with HPT. It should be noted that the present data was plotted using $s=0$ in eq.(1) and this may result in overestimation of the equivalent strain. Nevertheless, the data points for $\mathrm{Al}, \mathrm{Cu}$ and $\mathrm{Fe}$ are still on the steady state levels.

An orientation image by EBSD is shown in Fig. 6(a) for Al after CHPT. TEM bright-field micrographs including SAED patterns are in Figs. 6(b), (c) and (d) for Al, Cu and Fe after CHPT, respectively. Inspection of Figs. 6(a) and (b) reveals that few dislocations are visible in the grains and that grain boundaries are straight and well defined with an average grain size of $\sim 2.1 \mu \mathrm{m}$ in Al. These microstructural features are consistent with the earlier observation using conventional HPT, where an average grain size of $\sim 1.9 \mu \mathrm{m}$ was reported [15]. However, this is higher than the grain sizes of $\sim 1.2 \mu \mathrm{m}$ reported for ECAP-processed samples [16, 17]. The difference in the grain size may be due to the difference in microstructural evolution during HPT and ECAP. It is apparent from Figs. 6(c) and (d) that in $\mathrm{Cu}$ and Fe subjected to CHPT, the grain size is at submicrometer level with many grain boundaries ill-defined, having high angles of misorientation as evident from the SAED patterns with well defined rings. It was confirmed that most of grains contain many dislocations but there are a few grains with a low density of dislocations. These microstructural features are also consistent with our earlier reports for HPT processing of $\mathrm{Cu}$ [10] and Fe [11].

In summary, it is emphasized that the method of CHPT can provide a continuous process for the conventional HPT while achieving grain refinement and subsequent strengthening in metallic materials without sacrificing the advantages of the conventional HPT. The method of CHPT has two main merits when compared to HPT and other SPD processing methods: first, a saturated level of hardness and a minimum grain size are reached in short time and after one pass through the anvils; second, CHPT can be used as a continuous process for producing metallic sheets and wires.

\section{Summary and conclusions}

A new severe plastic deformation process, called continuous high-pressure torsion (CHPT), was developed for microstructural refinement and subsequent enhancement of hardness. Sheets of high purity $\mathrm{Al}, \mathrm{Cu}$ and $\mathrm{Fe}$ with rectangular cross sections, $0.6 \mathrm{~mm}$ thickness and $3 \mathrm{~mm}$ width, were successfully processed by torsional straining under high pressure using CHPT.

\section{Acknowledgements}

One of the authors (KE) thanks the Islamic Development Bank for a scholarship. This work was supported in part by the Light Metals Educational Foundation of Japan, in part by a Grant-in-Aid for Scientific Research from the Ministry of Education, Culture, Sports, Science and Technology of Japan in the Priority Area "Giant Straining Process for Advanced Materials Containing Ultra-High Density Lattice Defects" and in part by Kyushu University Interdisciplinary Programs in Education and Projects in Research Development (P\&P). 


\section{References}

[1] Valiev RZ, Islamgaliev RK, Alexandrov IV (2000) Prog Mater Sci 45:103.

[2] Valiev RZ, Estrin Y, Horita Z, Langdon TG, Zehetbauer MJ, Zhu YT (2006) JOM 58(4):33.

[3] Kolobov YR, Kieback B, Ivanov KV, Weissgaerber T, Girsova NV, Pochivalov YI, Grabovetskaya GP, Ivanov MB, Kazyhanov VU, Alexandrov IV (2003) Int J Refract Met Hard Mater 21:69.

[4] Wei Q, Zhang HT, Schuster BE, Ramesh KT, Valiev RZ, Kecskes LJ, Dowding RJ, Magness L, Cho K (2006) Acta Mater 54:4079.

[5] Rentenberger C, Waitz T, Karnthaler HP (2007) Mater Sci Eng A 462:283.

[6] Bridgman PW (1935) Phys Rev 48:825.

[7] Harai Y, Ito Y, Horita Z (2008) Scripta Mater 58:469.

[8] Erbel S (1979) Met Techno 6:482.

[9] Saunders I, Nutting J (1984) Metal Sci 18:571.

[10] Edalati K, Fujioka T, Horita Z (2008) Mater Sci Eng A 497:168.

[11] Edalati K, Fujioka T, Horita Z (2009) Mater Trans 50:44.

[12] Edalati K, Horita Z (2009) Mater Trans 50:92.

[13] Fujioka T, Horita Z (2009) Mater Trans 50:930.

[14] Edalati K, Horita Z, Langdon TG (2009) Scripta Mater 60:9.

[15] Edalati K, Ito Y, Suehiro K, Horita Z (2009) Int J Mater Res 100(12):1668.

[16] Iwahashi Y, Horita Z, Nemoto M, Langdon TG (1998) Acta Mater 46: 3317.

[17] Kawasaki M, Horita Z, Langdon TG (2009) Mater Sci Eng A 524:143. 
Table 1. Hardness values on upper surface and lower surface including middle point of thickness for $\mathrm{Al}, \mathrm{Cu}$ and Fe samples with $O D=20$ and $30 \mathrm{~mm}$ after processing with CHPT.

\begin{tabular}{ccccccc}
\hline & \multicolumn{3}{c}{ Vickers Microhardness (Hv) } \\
& Upper & Middle & Lower & Upper & Middle & Lower \\
\hline Al (99.99\%) & 33 & 33 & 34 & 32 & 32 & 32 \\
$\mathrm{Cu}(99.99 \%)$ & 129 & 128 & 128 & 133 & 130 & 132 \\
$\mathrm{Fe}(99.96 \%)$ & 325 & 319 & 332 & 335 & 336 & 338 \\
\hline
\end{tabular}

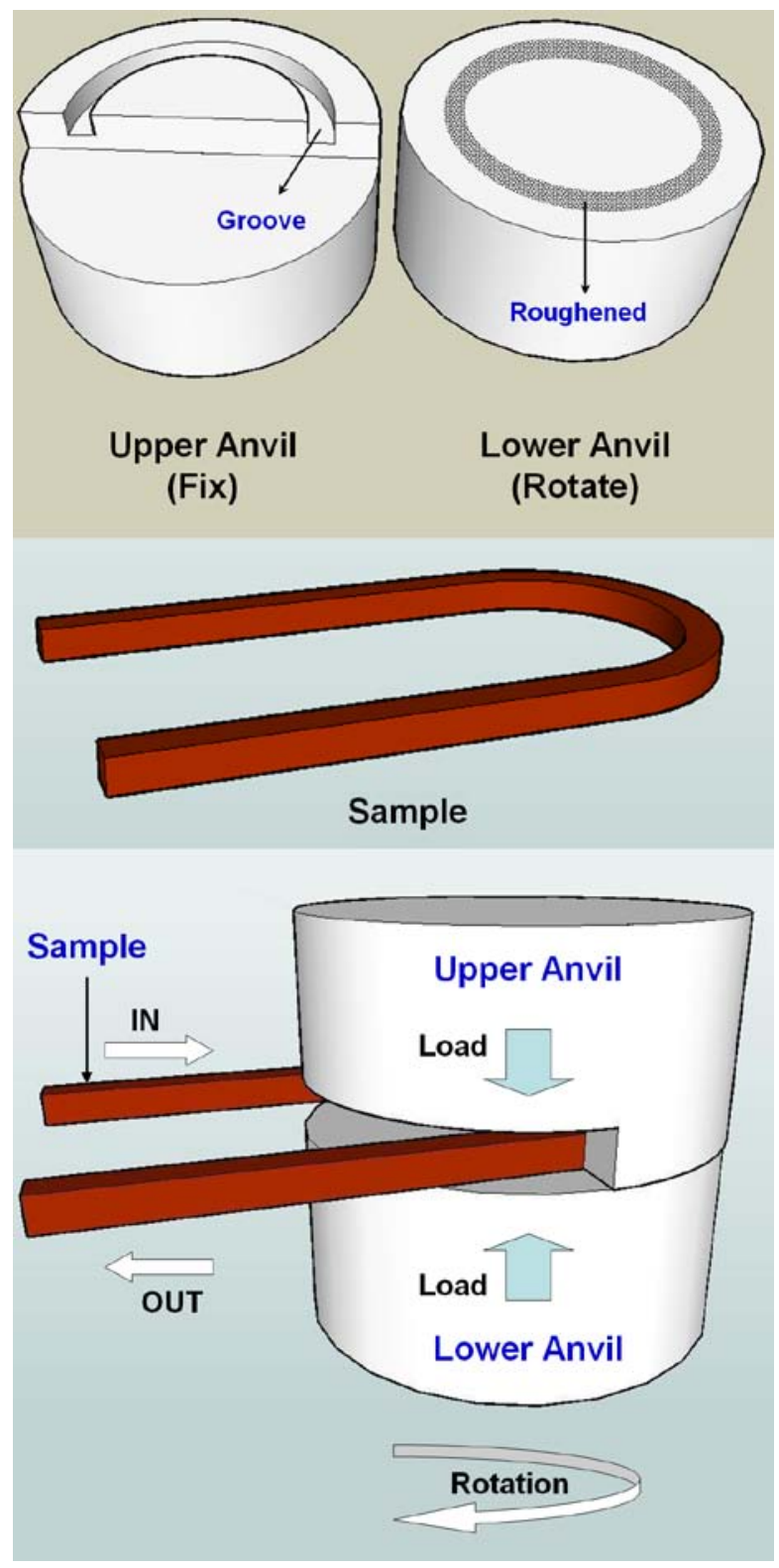

Figure 1. Schematic illustration of CHPT. 


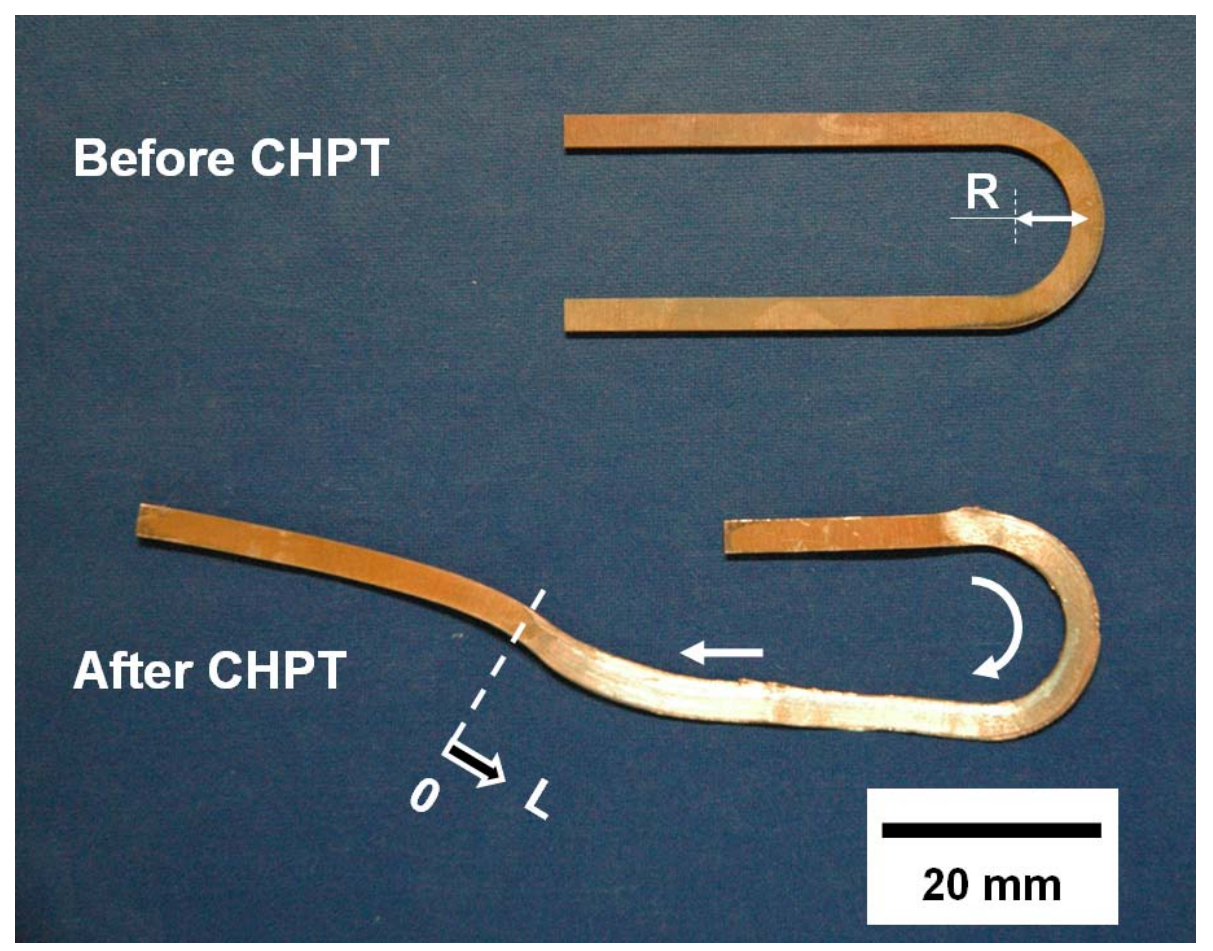

Figure 2. Appearance of U-shaped Cu sample with $O D=20 \mathrm{~mm}$ before and after CHPT for 1 revolution.

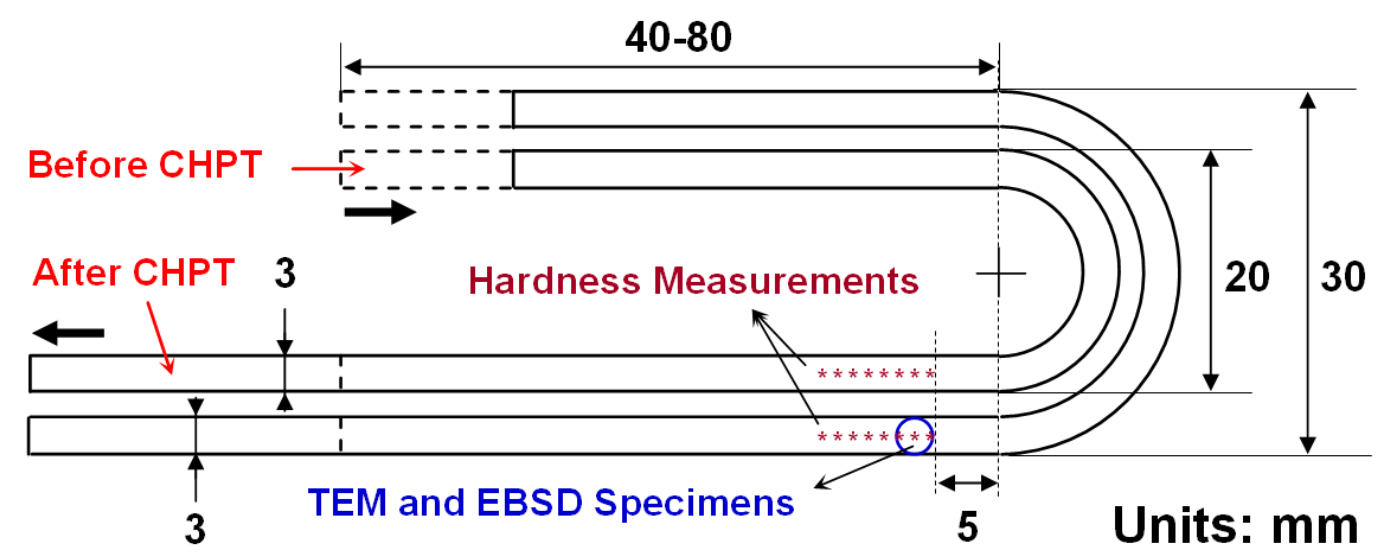

Figure 3. Dimensions of U-shaped samples including positions for microhardness measurements and locations for EBSD and TEM disc. 

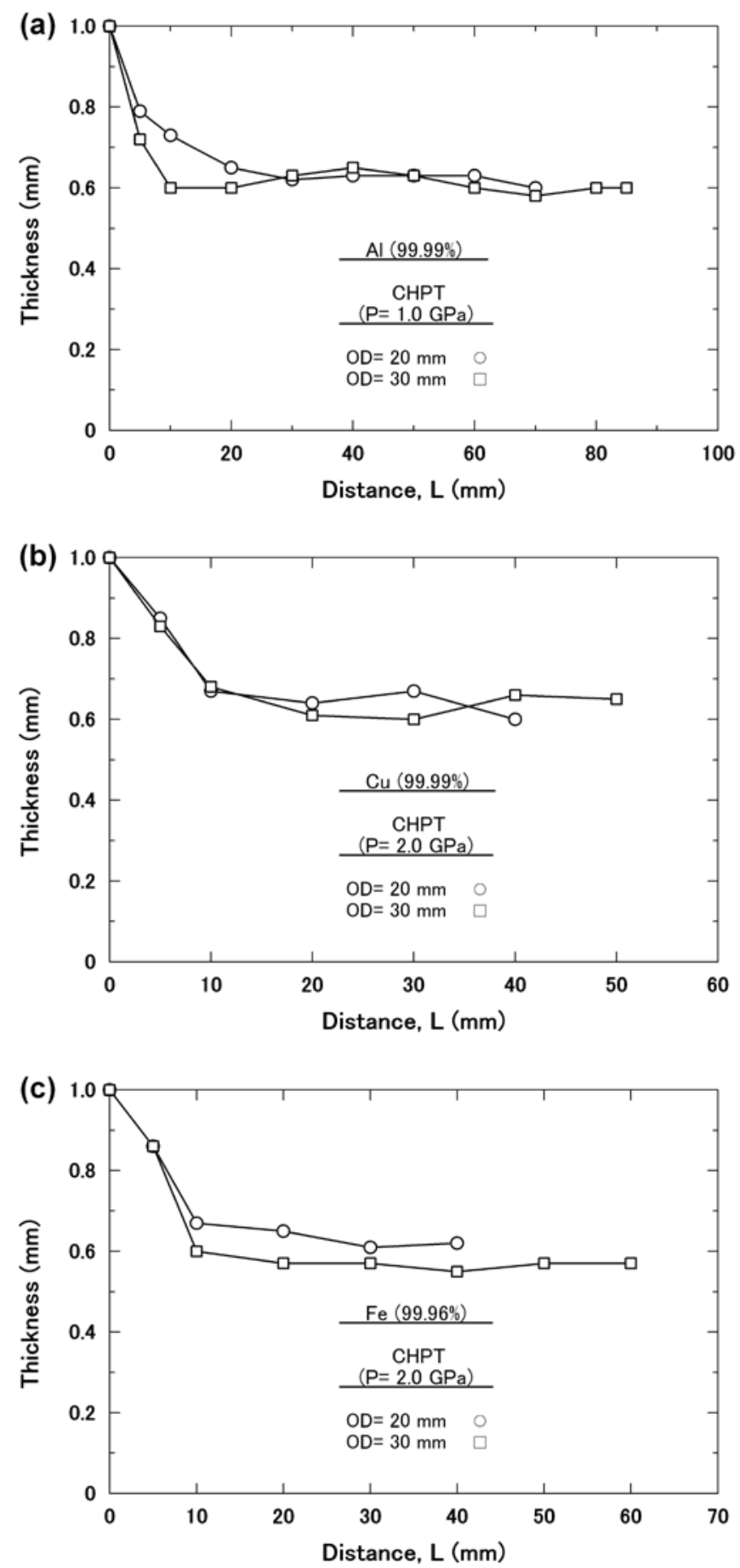

Figure 4. Thickness variation along longitudinal direction of (a) $\mathrm{Al}$, (b) $\mathrm{Cu}$ and (c) Fe samples after CHPT. 

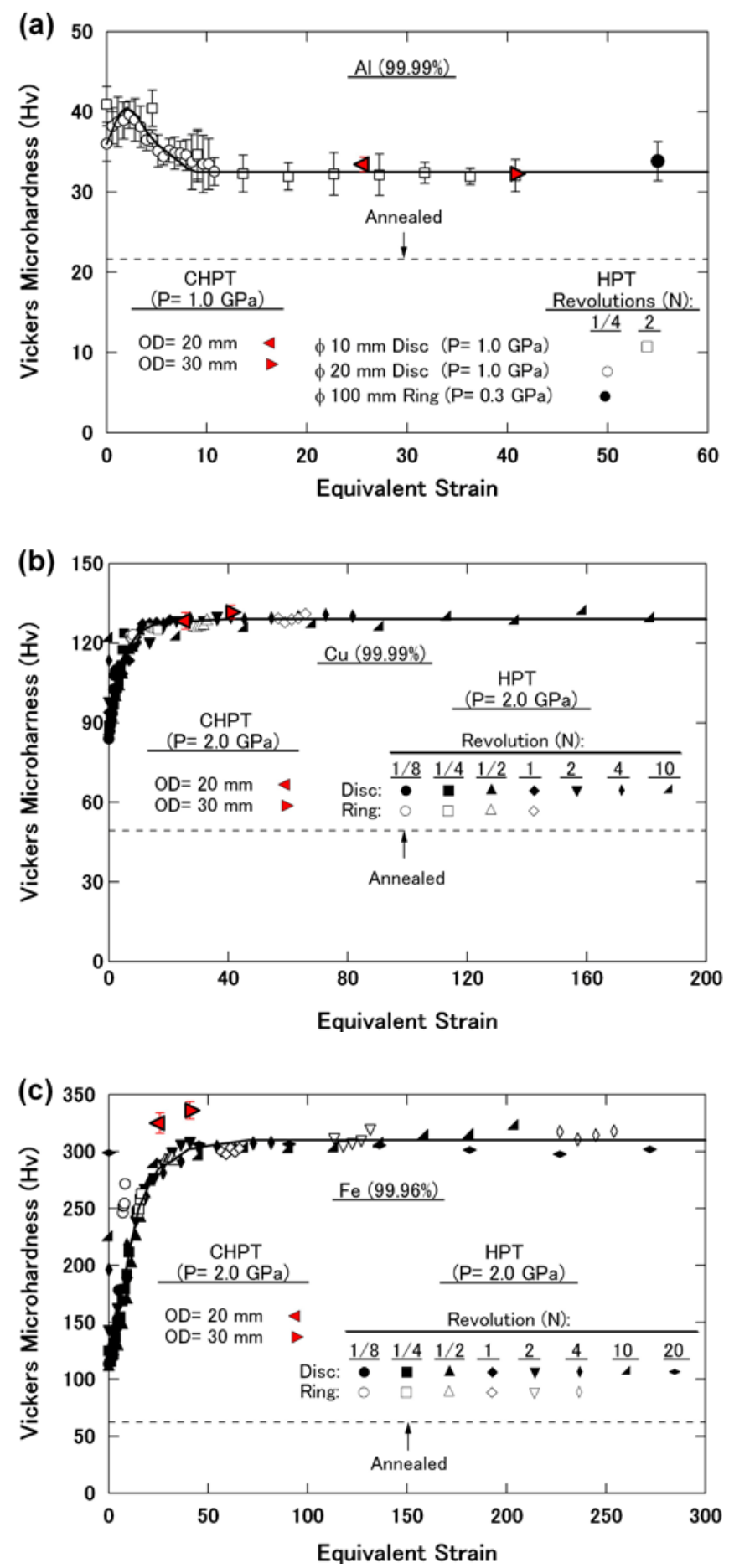

Figure 5. Plots of Vickers microhardness against equivalent strain obtained earlier using conventional HPT for disc and ring specimens of (a) Al [12], (b) $\mathrm{Cu}$ [10] and (c) Fe [11] including results of CHPT using U-shaped samples with $O D=20$ and $30 \mathrm{~mm}$. 

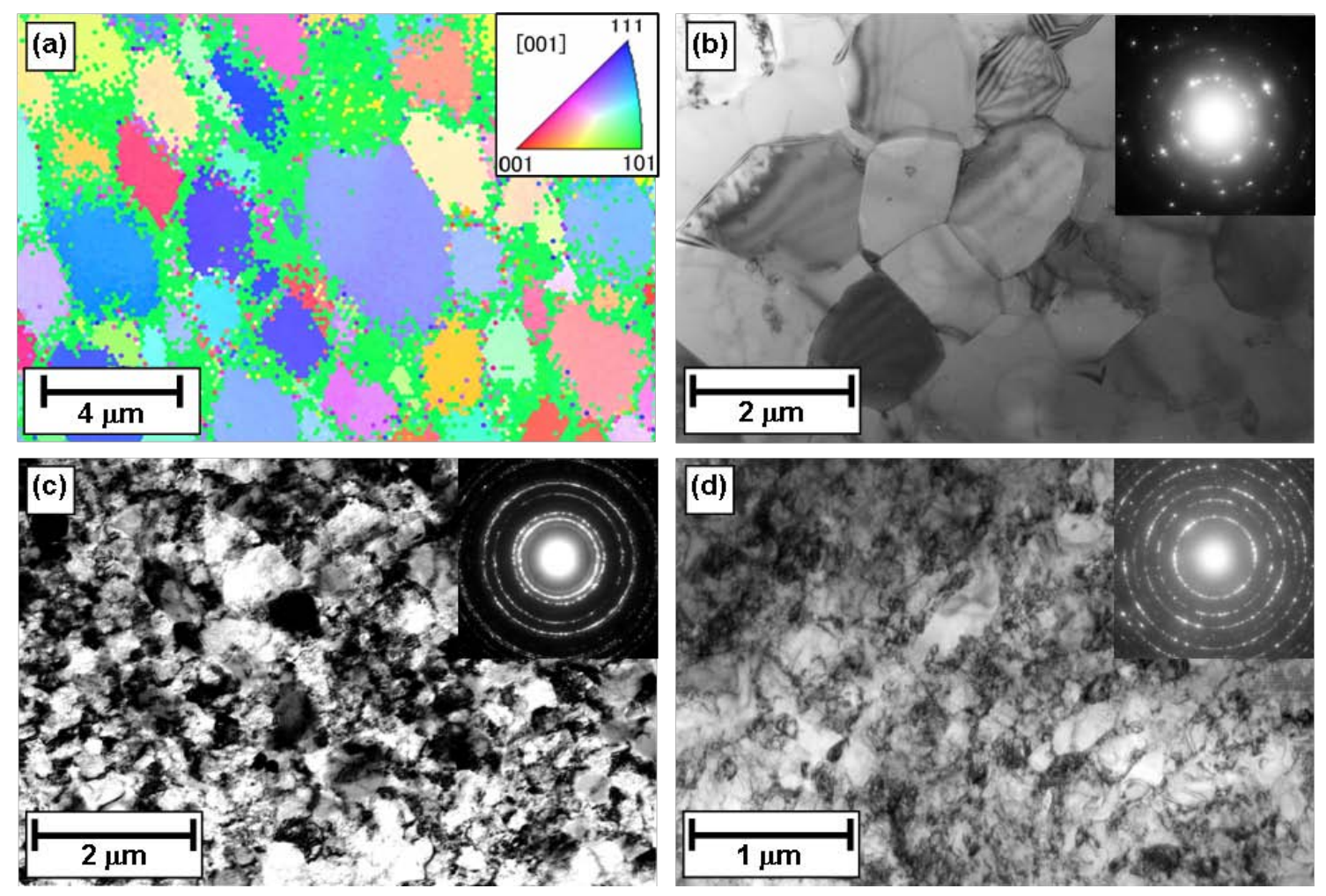

Figure 6. (a) EBSD orientation image of Al; TEM micrographs and SAED patterns of (b) Al, (c) $\mathrm{Cu}$ and (d) Fe after processing with CHPT. 